\title{
Comparação de Indicadores e Metodologia de Coleta para Estimativas de Produção Fecal e Fluxo de Digesta em Bovinos ${ }^{1}$
}

\section{Luís Carlos Vinhas Ítavo ${ }^{2}$, Sebastião de Campos Valadares Filho ${ }^{3}$, Fabiano Ferreira da Silva ${ }^{4}$, Rilene Ferreira Diniz Valadares ${ }^{3}$, Mario Fonseca Paulino ${ }^{3}$, Camila Celeste Brandão Ferreira Ítavo ${ }^{5}$, Eduardo Henrique Bevitori Kling de Moraes $^{5}$}

\begin{abstract}
RESUMO - Objetivou-se comparar a fibra em detergente ácido (FDAi) indigestível com o óxido crômico para estimar a produção de matéria seca fecal e as digestibilidades dos nutrientes de dietas de bovinos, em dois esquemas de coletas ( 2 ou 6 dias). Foram utilizados cinco bovinos da raça Nelore, não-castrados, com $165 \mathrm{~kg}$, fistulados no rúmen, abomaso é́leo. O delineamento foi em blocos casualizados com quatro tratamentos e cinco períodos de coleta. Os tratamentos consistiram de quatro níveis de concentrado na dieta (20, 40, 60 e $80 \%$ ), usando-se feno de capim-Tifton 85 como volumoso. A digestibilidade aparente da matéria seca (MS) foi menor quando estimada pelo óxido crômico, enquanto as digestibilidades da MS no rúmen e nos intestinos não diferiram entre os indicadores. Quando se comparou a metodologia de coleta (6 dias vs. 2 dias), não houve diferença para as digestibilidades totais e parciais dos nutrientes e também para a eficiência microbiana, demonstrando assim que a metodologia alternativa de dois dias de coleta pode ser utilizada para estimar a produção fecal e os fluxos de MS no abomaso e no íleo.
\end{abstract}

Palavras-chave: indicadores internos, indicadores externos, coleta de digesta, fluxo de matéria seca, digestibilidade ruminal

\section{Comparison of Markers and Collection Methodology for Fecal Production and Digesta Flow Estimates in Bovine}

\begin{abstract}
It was aimed to compare the internal markers, indigestible neutral detergent (NDFi) and acid fiber (ADFi), and ADFi with oxide chromic to esteem the dry matter fecal production and nutrients digestibility of diets of bovine, in two outlines of collections ( 2 or 6 days). For the comparison among internal markers, 32 Nelore growing bulls, with $240 \mathrm{~kg}$, were maintained under feedlot, receiving diets with different concentrate levels $(20,40,60$ and 80\%). For the comparison among internal and external marker, five $165 \mathrm{~kg}$ Nelore growing bulls, rumen, abomasum and ileum fistulated, were used. The design was in blocks with four treatments and 5 collection periods. The treatments consisted of four concentrate levels (20,40,60 and 80\%). The roughage used was Tifton 85 hay. The apparent digestibility of dry matter (DM) was smaller, when was estimated by oxide chromic, however the DM digestibility in the rumen and intestines did not differ among markers. When the collection methodology was compared ( 6 days vs. 2 days), there was not difference in all the studied variables, demonstrating the suggested alternative methodology as soon as can be used with safety for the estimates of fecal production and DM flows in the abomasum and ileum.
\end{abstract}

Key Words: internal markers, external markers, digest collection, dry matter flow, ruminal digestibility

\section{Introdução}

As pesquisas na área de nutrição de ruminantes vêm, há muitos anos, buscando alternativas para avaliar o valor nutricional dos alimentos. A estimativa de valores de digestibilidade é reconhecidamente um dos primeiros parâmetros do valor nutritivo do alimento. Todavia, experimentos para determinação de digestibilidade via coleta total de fezes são dispendiosos e ainda carecem de adaptação dos animais às gaiolas e às bolsas coletoras. $\mathrm{O}$ uso de indicadores naturais constituintes da dieta apresentam-se inalterados através do trato gastrintestinal e, vêm se constituindo como alternativa ao método de coleta total e aos indicadores externos, tais como o óxido crômico ou sesquióxido de cromo $\left(\mathrm{Cr}_{2} \mathrm{O}_{3}\right)$, que é o composto inorgânico mais utilizado em experimentos de digestibilidade.

A recuperação de frações indigestíveis do alimento é a base para os indicadores internos, que são utilizados em estudos nos quais são necessárias estimativas de digestibilidade (Van Soest, 1994). O erro

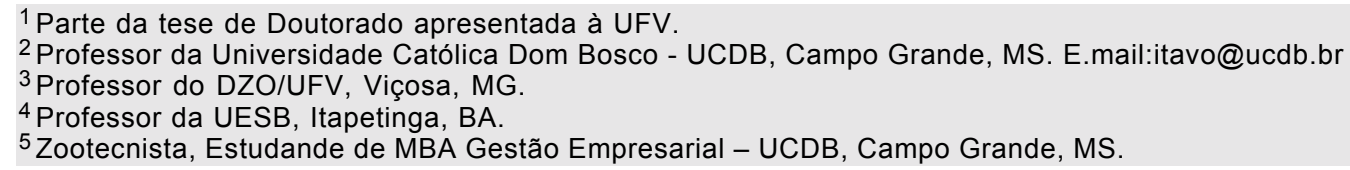


de amostragem pode ser reduzido se um componente indigestível de alta porcentagem na matéria seca puder ser encontrado. Nesse sentido, tem sido sugerido que as frações fibrosas indigestíveis do alimento sejam utilizadas com este propósito (Lippke et al., 1986).

Muitos são os indicadores internos que têm sido utilizados na estimativa da produção fecal: cinza insolúvel em ácido, cinza insolúvel em detergente ácido, lignina em detergente ácido indigestível, fibra em detergente neutro ou ácido indigestíveis. Entretanto, tais indicadores exigem longo período de incubação (Van Soest, 1994).

Recentemente, a porção fibrosa indigestível vem sendo utilizada como indicador interno. Os métodos de incubação utilizados são in situ e in vitro e as frações que têm demonstrado potencialidade como indicador são fibras em detergente neutro (FDNi) e ácido (FDAi) indigestíveis. Lippke et al. (1986), estudando o tempo de incubação para determinar a FDNi, observaram que, a partir de seis dias de incubação in vitro, o material estaria apto em representar a porção indigestível. Tais resultados foram confirmados posteriormente por Berchielli et al. (2000). Piaggio et al. (1991), avaliando os indicadores internos FDAi e lignina em detergente ácido indigestível (LDAi), observaram que a porcentagem de recuperação fecal da FDAi e da LDAi foram 92,9 e 101,9\%, respectivamente. Entretanto, a recuperação da FDAi diferiu de $100 \%$, enquanto a da LDAi não diferiu. Os autores atribuíram tal diferença à variação associada à digestão in situ e não foi descartada a possibilidade da FDAi se constituir em indicador interno promissor, porém justificariam novos esforços para superar as limitações metodológicas.

Berchielli et al. (1998), estudando em bovinos o fluxo de MS e MO no duodeno e suas digestibilidades estimadas por meio de indicadores internos (FDNi e FDAi) e externos (óxido crômico e cloreto de itérbio), observaram que a FDNi e a FDAi, quando usadas como indicadores, apresentaram menor variação e não diferiram entre si quanto à determinação da digestibilidade, enquanto os indicadores externos superestimaram o fluxo de MS e MO duodenal e, conseqüentemente, subestimaram os valores de digestibilidade.

Os indicadores FDNi, FDAi e lignina incubados por 144 horas apresentaram resultados semelhantes aos obtidos por coleta total de fezes em experimento realizado por Berchielli et al. (2000). Detmann (1999) estudou os indicadores internos FDAi, FDNi e MS indigestível (MSi) e encontrou que apenas FDNi e MSi constituíram a melhor alternativa para a determinação indireta da digestibilidade da dieta e do consumo de matéria seca, enquanto os valores obtidos pela FDAi apresentaram comportamento variável e superior aos valores obtidos com FDNi e MSi, porém inferiores aos valores de digestibilidade in vitro da MS. O autor atribuiu esse resultado à possibilidade de ocorrência de erro cumulativo, devido ao fato de as análises terem sido conduzidas de forma seqüencial.

Saliba et al. (1999), comparando diversos indicadores internos e externos com o método de coleta total de fezes, afirmaram que a média obtida com a FDAi foi a mais próxima à obtida pela coleta total, mostrando ter grande potencial como indicador para forragens, devido ao baixo custo e à facilidade metodológica. Porém, Ítavo et al. (2000), avaliando a digestibilidade de dois fenos de gramíneas do gênero Cynodon, por meio de estimativas obtidas por indicadores internos FDNi e FDAi, não observaram diferença significativa entre as estimativas dos coeficientes de digestibilidade aparente dos nutrientes para o feno de capim-coastcross. Todavia, para o feno de capim-Tifton 85 , houve diferença entre indicadores, sendo que a FDNi subestimou os resultados de digestibilidade.

Conhecendo-se o potencial de utilização do indicador interno FDAi, torna-se necessário elucidar o tempo de coleta ideal para sua utilização. Dessa forma, conduziu-se um experimento para estimar a produção de matéria seca fecal e os fluxos de matéria seca abomasal, calculados por indicadores interno (FDAi) ou externo $\left(\mathrm{Cr}_{2} \mathrm{O}_{3}\right)$, em dois esquemas de coletas ( 2 ou 6 dias).

\section{Material e Métodos}

O ensaio foi conduzido no Laboratório de Animais e no Laboratório de Nutrição Animal do Departamento de Zootecnia da Universidade Federal de Viçosa, em Viçosa, MG.

Foram avaliados dois indicadores para estimar a produção fecal: o óxido crômico $\left(\mathrm{Cr}_{2} \mathrm{O}_{3}\right)$, utilizado como indicador externo, e a fibra em detergente ácido indigestível (FDAi), como interno, para determinação da digestibilidade aparente dos nutrientes. Para a comparação entre indicadores, foram utilizados cinco novilhos da raça Nelore, não-castrados, com idade de oito meses e peso inicial médio de $165 \mathrm{~kg}$, fistulados no rúmen, abomaso e íleo, segundo as técnicas des-

R. Bras. Zootec., v.31, n.4, p.1833-1839, 2002 
critas por Leão \& Coelho da Silva (1980). Os animais foram mantidos em regime de confinamento, alojados em baias individuais cobertas, com piso de concreto revestido de borracha, de $3 \times 3 \mathrm{~m}$ de área, dotadas de comedouros de alvenaria e bebedouros individuais.

O delineamento experimental utilizado foi em blocos casualizados, em cinco períodos experimentais, com cinco animais, quatro tratamentos. Os tratamentos foram constituídos de feno de capim-Tifton 85 (Cynodon spp.) e mistura concentrada, que constituiu 20, 40, 60 e $80 \%$ da ração total (Tabelas 1,2 e 3). As dietas foram balanceadas de acordo com o NRC (1996). As rações foram isoprotéicas (15\% de PB) e tiveram aproximadamente $32 \%$ da PB na forma de compostos nitrogenados não-protéicos.

Os períodos experimentais tiveram duração de 21 dias cada, sendo 10 dias de adaptação à dieta e 11 dias para as coletas de fezes e digesta de abomaso e íleo; e conteúdo ruminal para isolamento de bactérias e $\mathrm{N}$-amoniacal. Os animais foram pesados ao início e ao final de cada período experimental.

A ração total foi fornecida à vontade, em uma única vez ao dia, às $7 \mathrm{~h} 30$, sendo as sobras recolhidas e pesadas diariamente, para determinação do consumo diário. A quantidade de ração fornecida foi calcu- lada de modo a permitir $10 \%$ de sobras, ao passo que a água foi fornecida à vontade.

Durante o período de coletas, foram realizadas amostras diárias dos alimentos e sobras no período de sete dias, a fim de se obter uma amostra composta por animal. Estas amostras, posteriormente, foram devidamente armazenadas a $-15^{\circ} \mathrm{C}$, moídas em moinho com peneira dotada de crivos de $1 \mathrm{~mm}$ e submetidas às análises laboratoriais, conforme Silva (1990).

Óxido crômico foi introduzido por intermédio da fístula ruminal, em uma única dose diária de $10 \mathrm{~g}$, durante seis dias no período de adaptação e nos dias de coleta de fezes e digestas de abomaso e íleo, sempre às $12 \mathrm{~h}$.

As coletas de fezes e digestas de abomaso e de íleo foram feitas uma vez ao dia. Utilizaram-se duas metodologias de coleta. Na primeira metodologia ( 2 dias), as coletas de digestas de abomaso e íleo e de fezes foram feitas em dois dias consecutivos, sendo no primeiro dia às $10 \mathrm{~h}$ e no segundo às $16 \mathrm{~h}$. Na segunda metodologia (6 dias), as coletas foram efetuadas em seis dias consecutivos, com intervalos de 26 horas entre coletas, iniciando-se às $8 \mathrm{~h}$ do dia 1 e terminando às $18 \mathrm{~h}$ do dia 6 .

As amostras de fezes e de digesta de abomaso

Tabela 1 - Proporção dos ingredientes nos concentrados, na base da matéria natural Table 1 - Proportion of the ingredients in the concentrates, on as fed basis

\begin{tabular}{|c|c|c|c|c|}
\hline \multirow[t]{2}{*}{$\begin{array}{l}\text { Ingredientes } \\
\text { Ingredients }\end{array}$} & \multicolumn{4}{|c|}{$\begin{array}{l}\text { Nível de concentrado na dieta }(\%) \\
\text { Level of concentrate in the diet }(\%)\end{array}$} \\
\hline & 20 & 40 & 60 & 80 \\
\hline Fubá de milho (\%) & 88,72 & 91,96 & 93,05 & 95,37 \\
\hline Corn starch (\%) & & & & \\
\hline $\begin{array}{l}\text { Farelo de soja (\%) } \\
\text { Soybean meal (\%) }\end{array}$ & 4,75 & 4,38 & 4,03 & 1,75 \\
\hline $\begin{array}{l}\text { Uréia }(\%) \\
\text { Urea }(\%)\end{array}$ & 2,93 & 1,57 & 1,16 & 1,25 \\
\hline $\begin{array}{l}\text { Calcário calcítico }(\%) \\
\text { Calcite limestone }(\%)\end{array}$ & 0,05 & 0,54 & 0,88 & 1,04 \\
\hline $\begin{array}{l}\text { Fosfato bicálcico }(\%) \\
\text { Dicalcium phosphate }(\%)\end{array}$ & 2,78 & 1,12 & 0,57 & 0,33 \\
\hline $\begin{array}{l}\text { Sal comum }(\%) \\
\text { Salt }(\%)\end{array}$ & 0,70 & 0,38 & 0,28 & 0,23 \\
\hline $\begin{array}{l}\text { Sulfato de zinco }(\mathrm{g} / 100 \mathrm{~kg}) \\
\text { Zinc sulfate }(\mathrm{g} / 100 \mathrm{~kg})\end{array}$ & 67,20 & 33,60 & 22,40 & 16,80 \\
\hline $\begin{array}{l}\text { Sulfato de cobre }(\mathrm{g} / 100 \mathrm{~kg}) \\
\text { Cupper sulfate }(\mathrm{g} / 100 \mathrm{~kg})\end{array}$ & 16,00 & 8,00 & 5,32 & 4,00 \\
\hline $\begin{array}{l}\text { Sulfato de cobalto }(\mathrm{g} / 100 \mathrm{~kg}) \\
\text { Cobalt sulfate }(\mathrm{g} / 100 \mathrm{~kg})\end{array}$ & 0,21 & 0,10 & 0,07 & 0,05 \\
\hline $\begin{array}{l}\text { Iodato de potássio }(\mathrm{g} / 100 \mathrm{~kg}) \\
\text { Potassium iodate }(\mathrm{g} / 100 \mathrm{~kg})\end{array}$ & 0,42 & 0,21 & 0,14 & 0,105 \\
\hline $\begin{array}{l}\text { Selenito de sódio }(\mathrm{g} / 100 \mathrm{~kg}) \\
\text { Sodium selenite }(\mathrm{g} / 100 \mathrm{~kg})\end{array}$ & 0,21 & 0,105 & 0,07 & 0,05 \\
\hline
\end{tabular}

R. Bras. Zootec., v.31, n.4, p.1833-1839, 2002 
Tabela 2 - Teores médios de matéria seca (MS), matéria orgânica (MO), proteína bruta (PB), extrato etéreo (EE), fibra em detergente neutro (FDN), carboidratos não-fibrosos (CNF), cálcio (Ca) e fósforo (P) dos concentrados e do feno

Table 2 - Average contents of dry matter (DM), organic matter (OM), crude protein (CP), ether extract (EE), neutral detergent fiber $(N D F)$, non fiber carbohydrates (NFC), calcium (Ca) and phosphorus ( $P$ ) of concentrates and hay

\begin{tabular}{|c|c|c|c|c|c|}
\hline \multirow[t]{2}{*}{ Itens } & \multirow[t]{2}{*}{$\begin{array}{c}\text { Feno } \\
\text { Hay }\end{array}$} & \multicolumn{4}{|c|}{$\begin{array}{l}\text { Nível de concentrado na dieta }(\%) \\
\text { Level of concentrate in the diet }(\%)\end{array}$} \\
\hline & & 20 & 40 & 60 & 80 \\
\hline $\mathrm{MS}(D M), \%$ & 88,55 & 87,30 & 87,29 & 87,33 & 88,55 \\
\hline $\mathrm{MO}(O M)^{1}$ & 94,18 & 95,77 & 96,37 & 97,02 & 96,55 \\
\hline $\mathrm{PB}(C P)^{1}$ & 14,09 & 21,98 & 16,62 & 15,78 & 14,63 \\
\hline $\mathrm{EE}$ & 1,93 & 2,78 & 4,30 & 2,66 & 1,89 \\
\hline FDN $(N D F)^{1,2}$ & 74,47 & 14,01 & 9,86 & 13,53 & 13,81 \\
\hline $\mathrm{CNF}(N F C)^{1}$ & 3,69 & 57,00 & 65,59 & 65,05 & 66,22 \\
\hline $\mathrm{Ca}^{1}$ & 0,36 & 0,96 & 0,70 & 0,71 & 0,84 \\
\hline $\mathrm{P}^{1}$ & 0,20 & 0,95 & 0,48 & 0,40 & 0,50 \\
\hline
\end{tabular}

$1 \%$ na matéria seca (\% in dry matter).

${ }^{2}$ FDN corrigida para cinzas e proteína (NDF corrected for ash and protein).

e íleo foram pré-secas em estufa de ventilação forçada, a $65^{\circ} \mathrm{C}$ por 96 horas, e processadas em moinho com peneira de $1 \mathrm{~mm}$. Finalmente, foi elaborada uma amostra composta por animal e por metodologia de coleta ( 2 dias vs. 6 dias) em cada período, com base no peso seco. As amostras compostas foram devidamente acondicionadas e posteriormente submetidas às análises laboratoriais.

Os teores de matéria seca (MS), matéria orgânica $(\mathrm{MO})$, proteína bruta $(\mathrm{PB})$, extrato etéreo (EE) e fibras em detergente neutro (FDN) e ácido (FDA) e a dosagem de nitrogênio total foram determinados em todas as amostras, conforme técnicas descritas por Silva (1990). As análises de cromo nas fezes e nas digestas de abomaso e íleo foram realizadas de acordo com técnica proposta por Williams et al. (1962), citados por Silva (1990).

Os carboidratos totais (CHOT) foram obtidos por intermédio da equação $100-(\% \mathrm{~PB}+\% \mathrm{EE}+$ \%Cinzas) (SNIFFEN et al., 1992). Os carboidratos não-fibrosos (CNF) foram obtidos pela diferença entre CHOT e FDN. Os teores de nutrientes digestíveis totais (NDT) foram obtidos conforme recomendações de Sniffen et al. (1992).

As variáveis estudadas, consumo e digestibilidade dos nutrientes, foram avaliadas por meio de análise de variância, utilizando-se o Sistema de Análises Estatísticas e Genéticas - SAEG (UFV, 1997).

Tabela 3 - Teores médios de matéria seca (MS), matéria orgânica (MO), proteína bruta (PB), extrato etéreo (EE), fibra em detergente neutro (FDN), carboidratos não-fibrosos (CNF), nutrientes digestíveis totais (NDT), cálcio (Ca) e fósforo $(P)$ das dietas experimentais

Table 3 - Average contents of dry matter (DM), organic matter (OM), crude protein (CP), ether extract (EE), neutral detergent fiber (NDF), non fiber carbohydrates (NFC), total digestible nutrients (TDN), calcium (Ca) and phosphorus ( $P$ ) of experimental diets

\begin{tabular}{|c|c|c|c|c|}
\hline \multirow[t]{2}{*}{ Itens } & \multicolumn{4}{|c|}{$\begin{array}{l}\text { Nível de concentrado na dieta }(\%) \\
\text { Level of concentrate in the diet }(\%)\end{array}$} \\
\hline & 20 & 40 & 60 & 80 \\
\hline $\mathrm{MS}(D M), \%$ & 88,21 & 88,05 & 87,79 & 87,58 \\
\hline $\mathrm{MO}(O M)^{1}$ & 94,50 & 95,06 & 95,88 & 96,08 \\
\hline $\mathrm{PB}(C P)^{1}$ & 15,67 & 15,10 & 15,11 & 14,52 \\
\hline $\mathrm{EE}^{1}$ & 2,30 & 3,03 & 2,46 & 1,95 \\
\hline FDN $(N D F)^{1,2}$ & 62,37 & 48,62 & 37,90 & 25,94 \\
\hline $\mathrm{CNF}(N F C)^{1}$ & 14,16 & 28,31 & 40,41 & 53,67 \\
\hline $\operatorname{NDT}(T D N)^{1}$ & 73,80 & 77,73 & 79,61 & 81,94 \\
\hline $\mathrm{Ca}^{1}$ & 0,48 & 0,50 & 0,57 & 0,74 \\
\hline $\mathrm{P}^{1}$ & 0,35 & 0,31 & 0,32 & 0,44 \\
\hline
\end{tabular}

$1 \%$ na matéria seca (\% in dry matter).

2 FDN corrigida para cinzas e proteína (NDF corrected for ash and protein).

R. Bras. Zootec., v.31, n.4, p.1833-1839, 2002 


\section{Resultados e Discussão}

$\mathrm{Na}$ Tabela 4 são apresentadas as digestibilidades aparentes totais e parciais da matéria seca (MS), em função dos indicadores e metodologias de coleta. As médias para os coeficientes de digestibilidade aparente total da matéria seca obtidas pelo $\mathrm{Cr}_{2} \mathrm{O}_{3}$ foram menores $(\mathrm{P}<0,05)$ que a estimada pelo FDAi. Entretanto, quando se comparou a metodologia de coleta,

Tabela 4 - Médias para os coeficientes de digestibilidade aparente da matéria seca (CDMS), digestibilidade ruminal da matéria seca (CDRMS), digestibilidade da matéria seca no intestino delgado (CDID), digestibilidade da matéria seca no intestino grosso (CDIG), em função dos indicadores e do período de coleta

Table 4 - Means for the coefficients of apparent dry matter digestibility (CDMS), dry matter ruminal digestibility (CDMRD), dry matter digestibility in the thin intestine (CDTI), dry matter digestibility in the large intestine (CDLI), in function of markers and collection period

\begin{tabular}{|c|c|c|c|}
\hline \multirow[t]{2}{*}{$\begin{array}{l}\text { Indicadores } \\
\text { Markers }\end{array}$} & \multicolumn{2}{|c|}{$\begin{array}{l}\text { Período de coleta } \\
\text { Collection period }\end{array}$} & \multirow[t]{2}{*}{$\begin{array}{l}\text { Média } \\
\text { Mean }\end{array}$} \\
\hline & $\begin{array}{l}6 \text { dias } \\
6 \text { days }\end{array}$ & $\begin{array}{l}2 \text { dias } \\
2 \text { days }\end{array}$ & \\
\hline \multicolumn{4}{|c|}{$\begin{array}{l}\text { Digestibilidade aparente } \\
\text { Apparent digestibility }\end{array}$} \\
\hline $\operatorname{Cromo}\left(\mathrm{Cr}_{2} \mathrm{O}_{3}\right)$ & 57,83 & 58,53 & $58,18^{\mathrm{B}}$ \\
\hline FDAi & 63,63 & 62,87 & 63,25 \\
\hline Média & $60,73^{\mathrm{a}}$ & $60,70^{\mathrm{a}}$ & - \\
\hline
\end{tabular}

Mean

Digestibilidade ruminal Ruminal digestibility

$\begin{array}{lllc}\text { Cromo }\left(\mathrm{Cr}_{2} \mathrm{O}_{3}\right) & 53,34 & 58,11 & 55,72^{\mathrm{A}} \\ \text { FDAi } & 53,74 & 56,45 & 55,10^{\mathrm{A}} \\ \text { Média } & 53,54^{\mathrm{a}} & 57,2 \$^{\mathrm{a}} & -\end{array}$

Mean

Digestibilidade no intestino delgado Digestibility in the small intestine

$\begin{array}{lllc}\text { Cromo }\left(\mathrm{Cr}_{2} \mathrm{O}_{3}\right) & 29,81 & 29,60 & 29,71^{\mathrm{A}} \\ \text { FDAi } & 35,07 & 25,57 & 30,32^{\mathrm{A}} \\ \text { Média } & 32,44^{\mathrm{a}} & 27,59^{\mathrm{a}} & -\end{array}$

Mean

Digestibilidade no intestino grosso Digestibility in the large intestine

$\begin{array}{llll}\text { Cromo }\left(\mathrm{Cr}_{2} \mathrm{O}_{3}\right) & 16,85 & 12,29 & 14,57^{\mathrm{A}} \\ \text { FDAi } & 11,19 & 17,98 & 14,58^{\mathrm{A}} \\ \text { Média } & 14,02^{\mathrm{a}} & 15,13^{\mathrm{a}} & - \\ \text { Mean } & & & \end{array}$

1,2 Médias seguidas por letras iguais, minúscula na linha e maiúscula na coluna, não diferem pelo teste $\mathrm{F}(\mathrm{P}>0,05)$. Cromo $\left(\mathrm{Cr}_{2} \mathrm{O}_{3}\right)$ (Chromium); FDAi (ADFi); Média (Mean).

1,2 Means followed by the same letters, small within a row and capital in the column, do not differ $(P>.05)$ by $F$ test. as médias de digestibilidade aparente da MS não apresentaram diferença $(\mathrm{P}>0,05)$. Carvalho et al. (1997) apresentaram valores máximos de digestibilidade aparente da MS de 59,8\% para o nível de $42 \%$ de concentrado na dieta de zebuínos. Tal valor é semelhante aos valores apresentados na Tabela 4, considerando que o nível médio de concentrado na dieta foi $50 \%$. Porém, quando se comparam os valores obtidos com o indicador FDAi, os resultados estariam acima daqueles encontrados por Carvalho et al. (1997) e Dutra et al. (1997) para rações com baixos teores de fibra.

Os coeficientes de digestibilidade ruminal e intestinais não diferiram $(\mathrm{P}>0,05)$ entre indicadores $\mathrm{e}$ metodologias de coleta, sugerindo que o indicador interno pode ser considerado bom para as estimativas de fluxo de MS e, conseqüentemente, para digestibilidades aparentes parciais. Da mesma forma, Berchielli et al. (1998), estudando em bovinos o fluxo de MS e a digestibilidade estimados por meio de indicadores internos, observaram que FDNi e FDAi apresentaram menor variação e não diferiram entre si quanto à determinação da digestibilidade, enquanto os indicadores externos superestimaram o fluxo de MS duodenal e, conseqüentemente, subestimaram os valores de digestibilidade. Tais valores também foram observados por Valadares Filho (1985) em estudos com $\mathrm{Cr}_{2} \mathrm{O}_{3}$ como indicador.

Considerando que houve diferença entre indicadores para as digestibilidades da MS, as digestibilidades dos demais nutrientes foram comparadas em função das metodologias de coleta, utilizando-se FDAi como indicador. Observa-se que não houve diferença $(\mathrm{P}>0,05)$ entre as metodologias de coleta, sugerindo que dois dias de coleta de fezes e digesta são suficientes para estimar a produção de MS fecal e os fluxos de MS ruminal e intestinal (Tabela 5). Contrariamente, Fontes et al. (1996) sugeriram a necessidade de se efetuarem duas coletas diárias de fezes por sete dias. Esses autores utilizaram os indicadores internos CIA (cinza insolúvel em ácido clorídrico) e CIDA (cinza insolúvel em detergente ácido). Em experimentos mais recentes, Tibo et al. (2000) indicaram que a realização de coletas somente durante o dia seria suficiente para obtenção de amostras representativas das fezes e das digestas de abomaso e íleo. Essas coletas foram feitas em intervalos de oito horas, com intervalos de seis horas entre dias, utilizando-se um esquema com quatro dias de coletas, totalizando ao final 12 amostras. Tais relatos já indicam a possibili-

R. Bras. Zootec., v.31, n.4, p.1833-1839, 2002 
Tabela 5 - Médias dos coeficientes de digestibilidade aparente total e parcial, em função da metodologia de coleta ( 6 dias vs. 2 dias), utilizando FDAi como indicador interno

Table 5 - Means of the coefficients of apparent total and partial digestibility, in function of the collection methodology (6 days vs. 2 days), using ADFi as internal marker

\begin{tabular}{|c|c|c|}
\hline \multirow[t]{2}{*}{$\begin{array}{l}\text { Variáveis } \\
\text { Variables }\end{array}$} & \multicolumn{2}{|c|}{$\begin{array}{l}\text { Período de coleta } \\
\text { Collection period }\end{array}$} \\
\hline & $\begin{array}{l}6 \text { dias } \\
6 \text { days }\end{array}$ & $\begin{array}{l}2 \text { dias } \\
2 \text { days }\end{array}$ \\
\hline & \multicolumn{2}{|c|}{$\begin{array}{l}\text { Digestibilidade aparente } \\
\text { Apparent digestibility }\end{array}$} \\
\hline MS & $63,63^{\mathrm{a}}$ & $62,90^{\mathrm{a}}$ \\
\hline MO & $65,85^{\mathrm{a}}$ & $65,16^{\mathrm{a}}$ \\
\hline PB & $59,02^{\mathrm{a}}$ & $58,96^{\mathrm{a}}$ \\
\hline $\mathrm{EE}$ & $72,50^{\mathrm{a}}$ & $70,81^{\mathrm{a}}$ \\
\hline CHOT & $66,50^{\mathrm{a}}$ & $66,23^{a}$ \\
\hline FDN & $78,30^{\mathrm{a}}$ & $77,56^{\mathrm{a}}$ \\
\hline \multirow[t]{2}{*}{ FDA } & $55,38^{\mathrm{a}}$ & $55,85^{\mathrm{a}}$ \\
\hline & \multicolumn{2}{|c|}{$\begin{array}{l}\text { Digestibilidade ruminal } \\
\text { Ruminal digestibility }\end{array}$} \\
\hline MS & $53,74^{\mathrm{a}}$ & $56,45^{\mathrm{a}}$ \\
\hline $\mathrm{MO}$ & $60,43^{\mathrm{a}}$ & $62,49^{a}$ \\
\hline PB & $11,33^{\mathrm{a}}$ & $4,80^{\mathrm{a}}$ \\
\hline $\mathrm{EE}$ & $-9,96^{a}$ & $1,41^{\mathrm{a}}$ \\
\hline CHOT & $67,85^{\mathrm{a}}$ & $71,36^{\mathrm{a}}$ \\
\hline \multirow[t]{2}{*}{ FDN } & $76,64^{\mathrm{a}}$ & $77,48^{\mathrm{a}}$ \\
\hline & \multicolumn{2}{|c|}{$\begin{array}{l}\text { Digestibilidade no intestino delgado } \\
\text { Digestibility in the small intestine }\end{array}$} \\
\hline MS & $35,07^{\mathrm{a}}$ & $25,57^{\mathrm{a}}$ \\
\hline $\mathrm{MO}$ & $35,47^{a}$ & $25,03^{\mathrm{a}}$ \\
\hline PB & $56,19^{\mathrm{a}}$ & $51,63^{\mathrm{a}}$ \\
\hline $\mathrm{EE}$ & $77,31^{\mathrm{a}}$ & $80,11^{\mathrm{a}}$ \\
\hline CHOT & $22,45^{\mathrm{a}}$ & $17,56^{\mathrm{a}}$ \\
\hline \multirow[t]{2}{*}{ FDN } & $16,57^{\mathrm{a}}$ & $12,43^{\mathrm{a}}$ \\
\hline & \multicolumn{2}{|c|}{$\begin{array}{l}\text { Digestibilidade no intestino grosso } \\
\text { Digestibility in the large intestine }\end{array}$} \\
\hline MS & $11,19^{\mathrm{a}}$ & $17,98^{\mathrm{a}}$ \\
\hline MO & $14,24^{\mathrm{a}}$ & $12,48^{\mathrm{a}}$ \\
\hline PB & $4,80^{\mathrm{a}}$ & $10,53^{\mathrm{a}}$ \\
\hline $\mathrm{EE}$ & $-1,62^{\mathrm{a}}$ & $-2,84^{\mathrm{a}}$ \\
\hline CHOT & $9,73^{\mathrm{a}}$ & $11,08^{\mathrm{a}}$ \\
\hline FDN & $6,79^{a}$ & $10,09^{\mathrm{a}}$ \\
\hline
\end{tabular}

Médias seguidas por letras iguais na linha não diferem pelo teste $\mathrm{F}(\mathrm{P}>0,05)$.

$M S=$ matéria seca; $M O$ = matéria orgânica; $P B=$ proteína bruta; $\mathrm{EE}=$ extrato etéreo; $\mathrm{CHOT}=$ carboidratos totais; FDN = fibra em detergente neutro; FDA = fibra em detergente ácido.

$M e a n s$ followed by the same letters within a row do not differ $(P>.05)$ by $F$ test. $D M=$ dry matter; $O M=$ organic matter; $C P=$ crude protein; $E E=$ ether extract; $T C H O=$ total carbohydrates; $N D F=$ neutral detergent fiber; $A D F=$ acid detergent fiber.

dade de redução do período de coleta e, conseqüentemente, o número de amostras de fezes e digesta para obtenção de resultados confiáveis de digestibilidade aparente total e parcial (Tabela 4).

Não houve diferença $(\mathrm{P}>0,05)$ para os coeficientes de digestibilidade aparente da MS no rúmen, no intestino delgado e grosso, que foram 53,74; 35,07 e 11,19\% para a coleta tradicional de seis dias e 56,$45 ; 25,57$ e $17,98 \%$ para a coleta de dois dias, respectivamente. Resultados semelhantes foram obtidos por Tibo et al. (2000), utilizando rações com 50\% de concentrado e fenos dos capins-braquiária e coastcross. A digestibilidade aparente ruminal da MS foi inferior aos valores relatados por Ladeira et al. (1999a), porém semelhantes aos 57,48\% de Dias et al. (2000a) e aos 53,02 e $47,58 \%$ de Bürger et al. (2000), para 45 e $60 \%$ de concentrado, respectivamente.

Os fluxos de compostos nitrogenados totais (N) e $\mathrm{N}$ microbiano (Nmic) presentes no abomaso, os carboidratos totais degradados no rúmen (CHODR), a eficiência microbiana e o consumo de NDT são apresentados na Tabela 6. Observa-se que nenhuma das variáveis foi influenciada pela metodologia de coletas. Dias et al. (2000b), avaliando a eficiência de síntese microbiana em novilhos com peso médio de $268 \mathrm{~kg}$, encontraram para o nível de 50\% de concentrado, utilizando feno de capim-coastcross, $60,77 \mathrm{~g} /$

Tabela 6 - Compostos nitrogenados totais (N) e N microbiano (NMic) presentes no abomaso, carboidratos totais degradados no rúmen (CHODR), eficiência microbiana, expressa em gNmic/kgCHODR e gMSmic/kg CHODR, e consumo de NDT, em função da metodologia de coleta

Table 6 - Total nitrogen compounds $(N)$ and microbial $N$ (NMic) present in the abomasum, total carbohydrates degraded in the rumen (DCHOR), microbial efficiency, expressed in $\mathrm{gNMic} / \mathrm{kg}$ DCHOR and gNMic/kg DCHOR, and TDN intake, in function of the collection methodology

\begin{tabular}{llll}
\hline Indicadores & \multicolumn{2}{c}{$\begin{array}{c}\text { Período de coleta } \\
\text { Markers }\end{array}$} & $\begin{array}{c}\text { Média } \\
\text { Mean }\end{array}$ \\
\cline { 2 - 2 } & 6 dias & 2 dias & \\
6 days & 2 days & \\
\hline
\end{tabular}

\begin{tabular}{lccc}
\hline \multicolumn{3}{c}{$\begin{array}{c}\text { Digestibilidade aparente } \\
\text { Apparent digestibility }\end{array}$} \\
\hline $\begin{array}{l}\text { N no abomaso (g/dia) } \\
\text { N in the abomasum (g/day) }\end{array}$ & 64,62 & 68,58 & 66,32 \\
$\begin{array}{l}\text { NMic no abomaso (g/dia) } \\
\text { NMic in the abomasum (g/day) }\end{array}$ & 51,26 & 60,75 & 55,07 \\
$\begin{array}{l}\text { CHODR (kg/dia) } \\
\text { DCHOR ( } \mathrm{kg} / \text { day) } \\
\text { gNMic/kg CHODR }\end{array}$ & 1,28 & 1,37 & 1,34 \\
$\begin{array}{l}\text { gNMic/kg DCHOR } \\
\text { gMSmic/kg CHODR }\end{array}$ & 40,81 & 45,91 & 42,94 \\
$\begin{array}{l}\text { gDMmic/kg DCHOR } \\
\text { Consumo de NDT (kg/dia) } \\
\text { NDT intake (kg/day) }\end{array}$ & 2,20 & 387,16 & 367,03 \\
\hline
\end{tabular}


dia de N microbiano no abomaso. Este valor é semelhante ao apresentado na Tabela 6.

A eficiência microbiana expressa em gMSmic $/ \mathrm{kg}$ CHODR foi, em média, 367,03 superior ao valor de 320,35 encontrado por Ladeira etal. (1999b), trabalhando com novilhos Nelore com peso médio de 244,6 kg. Dias et al. (2000b) encontraram 368,79 para o nível de 50\% de concentrado. Novamente, tais relatos confirmam a hipótese de utilização da metodologia de dois dias para coletas de fezes e de digestas de abomaso e de íleo.

\section{Conclusões}

Sugere-se que a FDAi pode ser utilizada para estimar os fluxos de matéria seca no abomaso, no íleo e nas fezes.

Recomenda-se a utilização de dois dias para a obtenção de amostras de fezes e de digestas de abomaso e íleo.

\section{Literatura Citada}

BERCHIELLI, T.T.; RODRIGUEZ, N.M.; OSÓRIO NETO, E. et al. Comparação de marcadores de fase sólida para medir fluxo de matéria seca e matéria orgânica no duodeno. Arquivo Brasileiro de Medicina Veterinária e Zootecnia, v.50, n.2, p.147-152, 1998.

BERCHIELLI, T.T.; ANDRADE, P.; FURLAN, C.L. Avaliação de indicadores internos em ensaios de digestibilidade. Revista Brasileira de Zootecnia, v.29, n.3, p.830-833, 2000.

BÜRGER, P.J.; PEREIRA, J.C.; COELHO DA SILVA, J.F. et al. Consumo e digestibilidade aparente total e parcial em bezerros holandeses alimentados com dietas contendo diferentes níveis de concentrado. Revista Brasileira de Zootecnia, v.29, n.1, p.206-214, 2000

CARVALHO, A.U.; VALADARES FILHO, S.C.; COELHO DA SILVA, J.F. et al. Níveis de concentrado em dietas de zebuínos. 1. Consumo e digestibilidade aparente. Revista Brasileira de Zootecnia, v.26, n.5, p.986-995, 1997.

DETMANN, E. Cromo e constituintes da forragem como indicadores, consumo e parâmetros ruminais em novilhos mesticos, suplementados, durante o período das águas. Viçosa, MG: Universidade Federal de Viçosa, 1999. 103p. Dissertação (Mestrado em Zootecnia) - Universidade Federal de Viçosa, 1999

DIAS, H.L.C.; VALADARES FILHO, S.C.; COELHO DA SILVA, J.F. et al. Consumo e digestões totais e parciais em novilhos F1 Limousin $\mathrm{x}$ Nelore alimentados com dietas contendo cinco níveis de concentrado. Revista Brasileira de Zootecnia, v.29, n.2, p.545-554, 2000a

DIAS, H.L.C.; VALADARES FILHO, S.C.; COELHO DA SILVA, J.F. et al. Eficiência de síntese microbiana, $\mathrm{pH}$ e concentrações ruminais de amônia em novilhos F1 Limousin $\mathrm{x}$ Nelore alimentados com dietas contendo cinco níveis de concentrado. Revista Brasileira de Zootecnia, v.29, n.2, p.555-563, 2000b.

DUTRA, A.R.; QUEIROZ, A.C.; PEREIRA, J.C. et al. Efeito dos níveis de fibra e das fontes de proteínas sobre o consumo e digestão dos nutrientes em novilhos. Revista Brasileira de Zootecnia, v.26, n.4, p.787-796, 1997.
FONTES, C.A.A.; OLIVEIRA, M.A.T.; LANA, R.P. et al. Avaliação de indicadores na determinação da digestibilidade em novilhos. Revista da Sociedade Brasileira de Zootecnia, v.25, n.3, p.529-539, 1996.

ÍTAVO, L.C.V.; SILVA, F.F.; VALADARES FILHO, S.C. et al. Digestibilidade de fenos de gramíneas do Gênero Cynodon através de indicadores internos. In: REUNIÃO ANUAL DA SOCIEDADE BRASILEIRA DE ZOOTECNIA, 37. 2000, Viçosa, MG. Anais... Viçosa, MG: Sociedade Brasileira de Zootecnia, 2000. p.401.

LADEIRA, M.M.; VALADARES FILHO, S.C.; COELHO DA SILVA, J.F. et al. Consumo de digestibilidades aparentes totais e parciais de dietas contendo diferentes níveis de concentrado, em novilhos Nelore. Revista Brasileira de Zootecnia, v.28, n.2, p.395-403, 1999a.

LADEIRA, M.M.; VALADARES FILHO, S.C.; LEÃO, M.I. et al. Eficiência microbiana, concentração de amônia e pH ruminal e perdas nitrogenadas endógenas em novilhos Nelore. Revista Brasileira de Zootecnia, v.28, n.2, p.404-411, 1999b

LEÂO, M.I ; COELHO DA SILVA, J.F. Técnicas de fistulação de abomaso em bezerros. In: CONGRESSO BRASILEIRO DE ZOOTECNIA, 1. REUNIÃO ANUAL DA SOCIEDADE BRASILEIRA DE ZOOTECNIA, 17., 1980, Fortaleza. Anais.. Fortaleza: Sociedade Brasileira de Zootecnia, 1980. p.37.

LIPPKE, H.; ELLIS, W.C.; JACOBS, B.F. Recovery of indigestible fiber from feces of sheep and cattle on forage diets. Journal of Dairy Science, v.69, n.2, p.403-412, 1986.

NATIONAL RESEARCH COUNCIL - NRC. Nutrient requirements of beef cattle. 7.ed. Washington, D.C. National Academy Press, 1996. 242p.

PIAGGIO, L.M.; PRATES, E.R.; PIRES, F.F. et al. Avaliação das cinzas insolúveis em ácido, fibra em detergente ácido indigestível e lignina em detergente ácido indigestível como indicadores internos da digestibilidade. Revista da Sociedade Brasileira de Zootecnia, v.20, n.3, p.306-312, 1991.

SALIBA, E.O.S.; RODRIGUEZ, N.M.; GONÇALVES, L.C. et al. Estudo comparativo da lignina isolada da palha de milho com outros indicadores em ensaio de digestibilidade aparente. In: REUNIÃO ANUAL DA SOCIEDADE BRASILEIRA DE ZOOTECNIA, 36., 1999, Porto Alegre, RS. Anais.. Sociedade Brasileira de Zootecnia: Porto Alegre. 1999.

SILVA, D.J. Análise de alimentos (Métodos químicos e biológicos). Viçosa, MG: Universidade Federal de Viçosa, 1990. 165p.

SNIFFEN, C.J.; O'CONNOR, J.D.; VAN SOEST, P.J. et al. A net carbohydrate and protein system for evaluating cattle diets. 2. Carbohydrate and protein availability. Journal of Animal Science, v.70, n.11, p.3562-3577, 1992.

TIBO, G.C.; VALADARES FILHO, S.C.; VALADARES, R.F.D. et al. Níveis de concentrado em dietas de novilhos mestiços F1 Simental x Nelore. 1. Consumo e digestibilidades. Revista Brasileira de Zootecnia, v.29, n.3, p.910-920, 2000.

UNIVERSIDADE FEDERAL DE VICOSA. Central de Processamento de dados (UFV/CPD). Manual de utilização do Programa SAEG (Sistema para Análises Estatísticas e Genéticas). Viçosa, MG: Universidade Federal de Viçosa, 1997. 59p.

VALADARES FILHO, S.C. Digestão total e parcial da matéria seca e carboidratos em bovinos e bubalinos. Viçosa, MG: Universidade Federal de Viçosa, 1985. 147p. Tese (Doutorado em Zootecnia) - Universidade Federal de Viçosa, 1985

Van SOEST, P.J. Nutritional ecology of the ruminant. Ithaca: Comstock Publ. Association, 1994. 476p.

Recebido em: 10/08/01 Aceito em: 10/04/02

R. Bras. Zootec., v.31, n.4, p.1833-1839, 2002 